\title{
Arbitraje Comercial Internacional en Chile: Una mirada jurisprudencial
}

Elina Mereniniskaya*

\begin{abstract}
SUMARIO
1. El marco histórico y normativo del arbitraje comercial internacional en Chile. 2. El alcance práctico del artículo 5 de la LACI. 3. Recurso de nulidad contra las sentencias arbitrales internacionales dictadas en Chile. 4 . Valor vinculante de un acuerdo arbitral internacional. 5. Medidas cautelares. 6. Reconocimiento de sentencias arbitrales extranjeras. 7. ¿Carácter ejecutoriado de la sentencia arbitral extranjera? Reconocimiento de una sentencia sujeta al proceso de anulación en el país de origen. 8. Conclusión.
\end{abstract}

\section{El MARCo histórico Y NORMATIVO DEL ARBITRAJE COMERCIAL INTERNACIONAL EN CHILE}

La legislación que rige el arbitraje en Chile remonta sus orígenes a fines del siglo XIX, más precisamente, a la Ley Orgánica de Tribunales del año 1875. Las disposiciones fundamentales por las que actualmente se rige el arbitraje interno o doméstico en Chile, se encuentran contempladas en el Título IX, Arts. 222 al 243 del Código Orgánico de Tribunales (COT) del año 1903 y

- Doctora y Magister en Derecho (Universidad de Göttingen, Alemania). Abogada (Universidad Rusa de Emmanuel Kant, Rusia). Consejera Especial para Arbitraje Internacional, Centro de Arbitraje y Mediación de la Cámara de Comercio de Santiago. Profesora de la Escucla de Graduados, Facultad de Derecho, Universidad de Chile. 
en el Título VIII del Libro III, Arts. 628 al 644 del Código de Procedimiento Civil (CPC) del año 1943.

El Art. 222 del COT consagra la naturaleza jurisdiccional del arbitraje interno de la siguiente manera: "Se llaman árbitros los jueces nombrados por las partes, o por la autoridad judicial en subsidio, para la resolución de un asunto litigioso". De esta manera, el arbitraje fue concebido como una jurisdicción análoga a la de los tribunales ordinarios. ${ }^{1}$ En esta misma línea, la jurisprudencia nacional ha señalado que "los árbitros están encargados de administrar justicin y desempeñan, por consiguiente, una función pública, toda vez que la jurisdicción es atributo exclusivo del Estado y sólo los órganos por él autorizados pueden ejercerla".2

El sistema jurídico chileno permite distinguir dos categorías de arbitraje doméstico: el arbitraje forzoso y el arbitraje voluntario. El arbitraje forzoso constituye la única vía que la ley consagra para resolver conflictos, cuya naturaleza particular requiere de una justicia amigable y eficiente, liberando con ello, al mismo tiempo, a los tribunales ordinarios de pleitos cargados de minuciosos detalles ${ }^{3}$. Aunque se cuestiona el carácter coercitivo con que se impone esa búsqueda de paz social ${ }^{\star}$, el arbitraje forzoso se ha transformado, en opinión de operadores jurídicos, en una herramienta práctica y eficaz ${ }^{5}$.

1. Aylwin, Patricio, El juicio arbitral, Ed. Juridica, Santiago, 2005, p. 49.

2. Conte de Apelaciones de Santiago, "Umutia con de la Maza", 29 de julio de 1986, pp. 80-82, El Arbitraje en la .harispradencia Chilena, CCS, Santiago, 2005.

3. Eyzaguirrc, Rafacl, El arbitraje comercial en la legislación chilena y su negulación internacional, Ed. Juridica de Chile, Santiago, 1981, p. 24; Aylwin, Patricio, op. cit., pp. 84.117, quien en base al Art. $227 \mathrm{del}$ COT distingue siete grupos de casos: La liquidación de una sociedad conyugal o de cierto tipo de sociedades y comunidades, la partición de bienes, juicios relativos a la presentación de cuentas, diferencias que ocurran entre socios de determinadas sociedades, cuestiones sobre derechos o repartición de aguas, negociación colectiva en materia laboral, y materias comerciales como la avería común, seguros y comercio maritimo.

4. Picand, Eduardo, Arbitraje comercial internacional, Tomo 1, Ed. Juridica, Santiago, 2005, pp. 54-56.

5. Acorde a los resultados de la encuesta de opinión de la comunidad juridica chilena, realizada por el CAM Santiago en el año 2010, cerca de un $45 \%$ de los cncuestados escogieron la opción de ampliar las materias sujetas al arbitraje forzoso y cerca del $40 \%$ estimaron que la situación actunl deberia mantenerse. 
La alta investidura de los árbitros, el hecho que "como jueces, están sujetos a la jurisdicción correccional, disciplinaria y económica que corresponde a la Corte Suprema sobre todos los tribunales de la nación", "y la modalidad del arbitraje forzoso, sin duda han contribuido a que muy tempranamente el arbitraje se haya convertido en un exitoso método de resolución de conflictos y se haya ganado el reconocimiento del mundo jurídico chileno. ${ }^{7}$

Ese escenario normativo fue complementado en el año 1992 por la creación de una primera institución dedicada a la administración de los arbitrajes. En particular, la Cámara de Comercio de Santiago estableció el Centro de Arbitraje y Mediación (CAM Santiago). A partir de ese momento, el número de causas sometidas al arbitraje institucional del CAM Santiago ha crecido de manera sostenida, superando hasta la fecha los mil doscientos arbitrajes.

En materia de arbitraje comercial internacional, rigen en Chile la Convención de Nueva York sobre el reconocimiento y la ejecución de las sentencias arbitrales extranjeras (Convención de Nueva York) y la Convención Interamericana de Panamá sobre arbitraje comercial internacional, ratificadas en el año 1975 y 1976 respectivamente. Como es sabido, estos instrumentos internacionales regulan dos aspectos fundamentales del arbitraje. En particular, obligan a los Estados a otorgar el reconocimiento a los pactos de sumisión al arbitraje y a los laudos arbitrales internacionales. Sin embargo, la vigencia de estas Convenciones no había significado mayor despliegue del arbitraje comercial internacional en Chile, dado que éste carecía de una regulación específica, susceptible de satisfacer las necesidades de la contratación transfronteriza contemporánea.

6. Aylwin. Patricio, op.cil., p. 462.

7. Jorquicra, Carlos Eugenio y Helmlinger, Karin, "Chile", en Blackaby, Niegel, Lindesey, David, Spinillo, Alessandro (Editores), International Arbitration in Latin America, Kluwer Law International, La Haya. 2002, pp. 89-110. 
La Ley 19.971 sobre Arbitraje Comercial Internacional (LACI) de 29 de septiembre del año 2004 vino a suplir justamente este vacío. La LACI ha incorporado al derecho chileno, en forma íntegra, la Ley Modelo de Arbitraje (LMA), elaborada, en el año 1985, por la Comisión de las Naciones Unidas para el Derecho Mercantil Internacional (CNUDMI en castellano o UNCITRAL en inglés). La Ley $\mathrm{N}^{\circ} 19.971$ regula arbitrajes que cumplen con el requisito de internacionalidad y comercialidad. La aplicabilidad de la Ley $\mathrm{N}^{\circ} 19.971$ exige, asimismo, que se cumpla un requisito territorial. Conforme con lo que dispone el Art. 1.2, la Ley se aplica cuando el lugar de arbitraje esté situado en el territorio de Chile. ${ }^{8}$ Siempre y cuando un arbitraje presente esas características, la aplicación de la LACI es automática y no tiene que ser pactada por las partes.

Según el Mensaje del Ejecutivo, la aprobación de la LACI se hizo necesaria debido a la integración del país a la economía mundial y, como consecuencia de ésta, era menester ofrecer a los nacionales chilenos los mecanismos legales que les permitieran resolver sus diferencias comerciales internacionales en Chile. Asimismo, se planteó la aspiración a que "nuestro país ocupe un lugar destacado como centro de arbitraje en el comercio internacional, especialmente a nivel latinoamericano". ${ }^{2}$ Dicha opción se presenta a partir del ámbito material de aplicación de la Ley $\mathrm{N}^{\circ} 19.971$. Éste se define, siguiendo los parámetros de la LMA, principalmente sobre la base de dos criterios. El primero de ellos se enfoca en las partes del procedimiento arbitral, y el segundo, está relacionado con elementos sustantivos de la disputa. ${ }^{10}$

En concordancia con la aspiración de transformar a Chile en un centro relevante de arbitraje internacional, resultan interesantes los criterios de internacionalidad relacionados con las

8. El mismo precepto admite cuatro excepciones de esta regla, en lo relativo a la aplicación de los artículos 8, 9, 35 y 36, los cuales se aplican sin importar dónde se encuentra la sede del arbitraje,

9. Mensaje 15-349. La discusión parlamentaria al Proyecto de Ley 19.971 está dispronible en la página web de la Cámara de Diputados, www.camara cl.

10. Redfern, Alan y Martin Hunter, Law and Practice of International Commencial Arbitration, $4^{*}$ Ed. Sweet \& Maxwell, Londres, 2004, pp. 13 y ss. 
partes de la disputa. Tales criterios de internacionalidad son aquellos que permiten usar a Chile como sede del arbitraje sin que el objeto de la controversia necesariamente tenga que estar relacionado con la economía chilena. Así, en virtud del Art. 1.3.a de la LACI, el arbitraje es internacional si las partes del acuerdo de arbitraje tienen sus establecimientos en Estados diferentes. Por ejemplo, esta causal se cumple si el acuerdo de arbitraje se celebra entre una empresa chilena y una ecuatoriana. Pero la causal también se observa si el acuerdo arbitral se perfecciona entre esta última y una sociedad brasileña. Asimismo, según el Art. 1.3.b.i de la LACI, el arbitraje es internacional, si las partes tienen sus establecimientos en un solo Estado, pero sitúan el lugar del arbitraje fuera de su territorio nacional. Este requisito se cumple, por ejemplo, cuando dos empresas ecuatorianas se someten a un arbitraje con sede en Chile.

Como es bien sabido, uno de los factores más relevantes que inciden en la selección de una determinada sede del arbitraje, corresponde a la postura de los tribunales nacionales con respecto al arbitraje comercial internacional. Transcurridos seis años desde la entrada en vigor de la Ley $\mathrm{N}^{\circ} 19.971$, interesa analizar su recepción por parte de los tribunales ordinarios. A continuación se presentan las sentencias dictadas por la justicia ordinaria chilena en aplicación de la LACI.

\section{El alCanCe práctico del artículo 5 de la LACI}

La autonomía del arbitraje comercial internacional frente a la justicia ordinaria refleja una de las ventajas de este procedimiento que permite a las partes diseñarlo según sus necesidades. Acorde con ello, a los tribunales domésticos únicamente se les asignan las funciones de supervisión y apoyo a los procesos arbitrales. Este principio se expresa en el artículo 5 de la Ley $\mathrm{N}^{\circ}$ 19.971, que estipula: "En los asuntos que se rijan por la presente ley, no intervendrá ningún tribunal salvo en los casos en que esta ley así lo 
disponga". Las pocas situaciones en las cuales la misma LACI permite tal intervención son las siguientes:"1

i. En los casos en los cuales una parte del acuerdo arbitral solicite al tribunal remitir el caso a arbitraje ante una cláusula de arbitraje válida (art. 8);

ii. En los casos en los que se pida la dictación de las medidas precautorias (arts. 9);

iii. En los casos relacionados con el nombramiento, recusación o sustitución de los árbitros, cuando no hay acuerdo de las partes sobre el procedimiento, como sería en el caso del arbitraje institucional, o cuando éste no se cumpla (arts. 11, 13 y 14);

iv. En los casos en que se pida la nulidad de la decisión afirmativa del tribunal arbitral acerca de su competencia (art. 16);

v. En los casos en los cuales el tribunal arbitral o una de las partes pida la asistencia de un tribunal ordinario para la práctica de pruebas (art. 27);

vi. En los casos en los cuales una de las partes solicite la nulidad del laudo (art. 34), y

vii. En los casos en los cuales se solicite la ejecución de un laudo (arts. 35 y 36).

El tenor literal del artículo 5 de la LACI causó una gran polémica durante los trámites legislativos e inicialmente fue removido por la Cámara de Diputados. Se logró su reincorporación al texto de la ley, pero la norma fue aprobada con el siguiente oficio del Tribunal Constitucional:

"El artículo $5^{\circ}$ del proyecto debía dejar a salvo la facultad que a aquélla otorga el artículo 79 de la Constitución Política de ejercer la superintendencia directiva, correccional y económica de todos los tribunales de la nación, e igualmente el conocimiento del recurso de inaplicabilidad por inconstitu-

11. Jiménez Figueres, Dyala y Armer Rios, Angie, "Notas sobre la nueva ley chilena de arbitraje comercial intemacional", Revista Chilena de Derecho Privado, No. 4, 2005, pp. 307-326. 
cionalidad de las leyes que le confiere el artículo 80 de la Carta Fundamental".

Asimismo, el Tribunal sostuvo que los preceptos legales

"dejan a salvo las atribuciones que la Constitución otorga a la Corte Suprema según quedó expuesto, así como también, las acciones jurisdiccionales que contempla la Carta Política a favor de quienes puedan verse afectados en sus derechos fundamentales por la aplicación de esta ley" (el recurso de protección).

La aplicación práctica del artículo 5 de la LACI, sin embargo, ha estado marcada por el reconocimiento de la naturaleza autónoma del arbitraje comercial internacional por parte de las Cortes chilenas. Así, en uno de los primeros fallos en aplicación de la Ley $\mathrm{N}^{\circ}$ 19.971, la Corte tuvo la oportunidad para indagar en este asunto, junto con analizar el ámbito temporal de su aplicación. En esa ocasión, la parte demandada en un arbitraje seguido ante el CAM Santiago, alegaba que el contrato se había suscrito con anterioridad a la entrada en vigor de la Ley $\mathrm{N}^{\circ} 19.971$ y que, por ello, el procedimiento arbitral tenía que someterse a las normas que rigen el arbitraje interno.12 De haber aceptado la Corte esta línea de argumentación, habría tenido que estimar que contra las resoluciones de los árbitros estaban disponibles todos los recursos propios del sistema de arbitraje doméstico. Dado que en esa ocasión, las partes del acuerdo de arbitraje no habían renunciado a los recursos -algo que en la práctica ocurre en la mayoría abrumante de los casos- el recurso de hecho intentado por la demandada eventualmente habría sido admisible.

Resolviendo sobre lo particular, la Corte de Apelaciones de Santiago sostuvo lo siguiente:

12. Corte de Apelaciones de Santiago, Rol N॰865-2006, 25 de mayo de 2006. Las sentencias citadas con su número de rol, pueden ser encontradas a través de la página oficial del Poder Judicial de Chile: www.poderjudicial.cl. 
“Es del caso concluir que por ser la Ley N”19.971 de carácter netamente procesal, rige desde el momento de su entrada en vigencia y las normas del Código de Procedimiento Civil y otras que regulaban estas materias al momento de celebrarse el contrato, no están comprendidas, en caso alguno, dentro de las que deben entenderse incorporadas al contrato a la fecha de su celebración. De esta forma es aquella la norma aplicable a la sazón y, de conformidad a lo establecido en el artículo $5^{\circ}$ antes transcrito, sólo cabe resolver que la resolución en que incide el recurso de hecho no es susceptible de apelación, por lo cual deberá ser desestimado".

En el contexto de ese mismo arbitraje, la parte demandada había intentado cuestionar la resolución del Presidente de la Cámara de Comercio de Santiago (CCS) acerca de la designación del árbitro de acuerdo al mandato otorgado por las partes. En esa resolución, asimismo, se señalaba que el procedimiento arbitral iba a estar sometido a la Ley $\mathrm{N}^{\circ} 19.971$ por cumplirse los requisitos de aplicación de ésta. Contra esta decisión la parte demandada recurrió de protección, invocando el inciso 4 del $\mathrm{N}^{\circ}$ 3 del artículo 19 de la Constitución chilena. Alegó que el recurrido se habría atribuido una facultad jurisdiccional y, pretendiendo ser un Tribunal de Justicia, dictó una resolución mediante la cual instruía y ordenaba al tribunal arbitral cómo debía abordar la resolución de la contienda.

Al rechazar el recurso de protección, la Corte de Apelaciones falló que la LACI rige en Chile desde el día 4 de septiembre de 2004 y que a la fecha en que se solicitó a la CCS la designación de árbitro, dicha ley ya tenía vigencia. Por lo tanto, el árbitro, en su resolución de fecha 26 de diciembre de 2005, no hizo sino aplicar una ley que ya regía en Chile en materia de arbitraje comercial internacional. Asimismo, señala la sentencia, que

"las partes acordaron someter sus disputas, controversias o diferencias, a arbitraje de acuerdo con las reglas del Centro de Arbitraje de la Cámara de Comercio de Santiago, y ésta aplica la Ley N $N^{\circ} 19.971$ en los casos de Arbitrajes Comerciales 
Internacionales, ya que es una garantía de certeza jurídica a las partes y demuestra, a la comunidad internacional, el funcionamiento adecuado e imparcial de la institucionalidad de nuestro país".13

En esta misma línea de decisiones jurisprudenciales favorables se enmarca un fallo más reciente, el cual declaró inadmisible el recurso de queja presentado contra una sentencia arbitral internacional dictada en Chile. El recurso de queja es regulado por el art. 545 del COT de Chile:

"El recurso de queja tiene por exclusiva finalidad corregir las faltas o abusos graves cometidos en la dictación de resoluciones de carácter jurisdiccional. Sólo procederá cuando la falta o abuso se cometa en sentencia interlocutoria que ponga fin al juicio o haga imposible su continuación o definitiva, y que no sean susceptibles de recurso alguno, ordinario o extraordinario, sin perjuicio de la atribución de la Corte Suprema para actuar de oficio en ejercicio de sus facultades disciplinarias".

En este caso, el recurso fue interpuesto contra la sentencia de un árbitro único que tuvo a su cargo el arbitraje desarrollado de conformidad con la Ley $\mathrm{N}^{\circ} 19.971$ y bajo las reglas del CAM Santiago. La Corte de Apelaciones de Santiago, reconociendo la aplicabilidad de la Ley $\mathrm{N}^{\circ} 19.971$, se refirió a artículo 34 de ésta, señalando que "sólo contempla el recurso de nulidad como única vía de impugnación del laudo que se dicte en un arbitraje como el de la especie, excluyendo asi aquel intentado por el actor". A continuación, la Corte sostuvo que,

"a mayor abundamiento, el recurrente pretende que por esta vía se modifique y enmiende la sentencia dictada en autos, efecto que el artículo 545 del Código Orgánico de Tribunales impide, atendido precisamente la existencia de un único recurso especial concebido para la revisión de la sentencia definitiva". ${ }^{14}$

13. Corte de Apelaciones de Santiago, Rol N 88-2006, 3 de mayo de 2006. 
Estas decisiones confirman que los recursos disponibles contra los laudos arbitrales internacionales dictados en Chile se limitan a uno solo, a saber, la petición de nulidad contemplada en el artículo 34 de la LACI.

\section{Recurso de nUlidad CONTRA las SENTENCIAS ARBITRALES INTERNACIONALES DICTADAS EN CHILE}

Hasta la fecha, un recurso de nulidad fue resuelto por los tribunales chilenos. El recurso fue presentado en contra de un laudo pronunciado por un árbitro ad hoc en un arbitraje internacional con sede en Santiago. ${ }^{15}$ La parte reclamante alegó que el laudo arbitral se fundó en información contenida en un documento emanado de un tercero que no había sido acompañado legalmente a los autos, cuyo contenido no había sido ratificado por ese tercero declarando como testigo en la causa y que no tuvo oportunidad de refutar, determinándose los perjuicios a través de meras especulaciones y no de las pruebas de la causa. De la misma forma, sostuvo que el laudo contraviene el orden público procesal al violentar su derecho a la defensa y el principio del debido proceso.

La Corte, en primer lugar, recordó que el recurso de nulidad

"viene a constituir un recurso extraordinario, de derecho estricto, donde la actuación del Tribunal se limita a verificar la concurrencia de las causales invocadas en relación a los hechos que las fundamentan. La acción otorga competencia a la Corte para examinar el cumplimiento de las formas del juicio arbitral, especialmente en cuanto a las garantías formales que la propia ley establece de modo imperativo, para asegurar una correcta génesis del laudo".

14. Corte de Apelaciones de Santiago, Rol 2363-2010, 23 de julio de 2010 .

15. Corte de Apelaciones de Santiago. Rol N 9134-2007, 4 de agosto de 2009. 
Con respecto al fondo del recurso, sostuvo que los documentos obtenidos de la base de datos que sirvieron para determinar los perjuicios

"no eran ajenos al proceso, ni por ende desconocidos para la recurrente, toda vez que la demandante los acompañó formalmente a fojas 578 , los refirió en su presentación de fojas 1.308 , así como en la audiencia de reconocimiento. Al estar en conocimiento de los mismos, no resulta tampoco efectivo que no tuviera oportunidad para refutarlos, sobre todo si se tiene en cuenta que hizo uso de la citación conferida cuando fueron acompañados, $y$ se encontraba presente en la diligencia de reconocimiento sin observar nada al respecto. Por lo demás, una vez puesto -el peritaje- en su conocimiento, pudo hacer -y así lo hizo- las observaciones que estimó pertinentes. En definitiva, la demandada siempre tuvo conocimiento que se utilizaría como base para determinar los perjuicios, la información proveniente de una base de datos pública, cuyo detalle se agregó al proceso, por lo que no es posible sostener que el sentenciador haya apoyado su fallo en elementos probatorios inexistentes en el proceso o pruebas que no fueron introducidas al debate".

Por último, la Corte recalcó que el medio de prueba cuestionado por la recurrente no era

"la prueba documental sino que la pericial, que tiene por finalidad auxiliar al Tribunal, en cuestiones de hecho, concretas, para las cuales se requiere de conocimientos especiales sobre alguna ciencia o arte, cuya naturaleza jurídica es distinta de la anterior y cuya eficacia se valora conforme a las reglas de la sana crítica, esto es, conforme a las reglas de la lógica, a las máximas de experiencia y a los aportes que surgen del desarrollo científico".

Por las razones expuestas, la Corte concluyó que no se habían configurado las causales invocadas por la recurrente y rechazó el recurso de nulidad. 
Actualmente, una nueva petición de nulidad de un laudo arbitral se encuentra en trámite ante la Corte de Apelaciones de Santiago. ${ }^{16}$ Hasta el momento en que se escriben estas líneas el procedimiento ha avanzando con respecto a una de las peticiones de la parte recurrente. En particular, ella invocó el art. 34.4 de la LACI, el que señala:

"El tribunal, cuando se le solicite la anulación de un laudo, podrá suspender las actuaciones de nulidad, cuando corresponda y cuando así lo solicite una de las partes, por un plazo que determine a fin de dar al tribunal arbitral la oportunidad de reanudar las actuaciones arbitrales o de adoptar cualquier otra medida que a juicio del tribunal arbitral elimine los motivos para la petición de nulidad".

\section{La Corte sostuvo que}

"el artículo 34 de la Ley $\mathrm{N}^{\circ} 19.971$ contempla una figura especial de suspensión, que requiere la remisión de los autos al árbitro para ello, y la concurrente suspensión por esta Corte del conocimiento del presente recurso, situación para la cual este tribunal no encuentra razones justificadas que lo ameriten, se rechaza la solicitud formulada por la compareciente". ${ }^{17}$

De esta manera, la tramitación de la petición de nulidad seguirá acorde al procedimiento establecido, debiendo ser incluido en tabla con la preferencia consagrada en el art. 34.5 de la LACI.

16. Corte de Apelaciones de Santiago, Rol N ${ }^{\circ}$ 1420-2010.

17. Resolución de la Corte de 11 de agosto de 2010. 


\section{VAlor Vinculante de UN ACUerdo ARBITRAL INTERNACIONAL}

Para poder hacer efectiva la sumisión al arbitraje, las partes de un contrato internacional deben preocuparse de celebrar un acuerdo de arbitraje válido y ejecutable. Con la expresión "acuerdo de arbitraje", la Ley $\mathrm{N}^{\circ} 19.971$ hace referencia tanto a "una cláusula compromisoria incluida en un contrato" como a "un acuerdo independiente" (art. 7.1).

Ambas formas del acuerdo de arbitraje poseen el mismo valor jurídico, y es irrelevante si el acuerdo de arbitraje se ha celebrado con anterioridad o con posterioridad al surgimiento de la disputa, o si indica o no los nombres de los árbitros. Desde el punto de vista de validez sustantiva, el acuerdo de arbitraje es obligatorio para las partes, a menos que un tribunal ordinario determine que tal acuerdo es nulo, ineficaz o de ejecución imposible (art. 8.1 de la LACI). Como es sabido, mientras este último aspecto pueda ser discutido ante la justicia nacional, se podrá iniciar o proseguir las actuaciones arbitrales y dictar un laudo (art. 8.2).

Hasta la fecha no se conocen fallos dictados por los tribunales chilenos en base a los arts. $7^{\circ}$ y $8^{\circ}$ de la LACI. Sin embargo, hay sentencias que confirman el valor vinculante de las cláusulas arbitrales internacionales, fundando esas decisiones más bien en principios jurídicos generales.

En el primero de estos casos, el contrato objeto del litigio había sido suscrito entre una empresa chilena y una sociedad norteamericana. ${ }^{18}$ La parte chilena presentó una demanda ante la justicia ordinaria chilena. El tribunal acogió la excepción de incompetencia presentada por la demandada. Para ello se basó en la cláusula de solución de controversias pactada por las partes. En particular, sostuvo que en ésta se había pactado una pró-

18. $21^{\circ}$ Juzgado Civil de Santiago, Rol N ${ }^{\circ} 16361-2006,2$ de noviembre de 2007. 
rroga de competencia, "mediante la cual cunlquier disputa o diferencia que surja entre las partes respecto de la interpretación de este contrato o de cualquier asunto que surja de este contrato o en relación con él, deberá resolverse de acuerdo con las leyes del Estado de Wisconsin". Más adelante la cláusula contemplaba la reserva del derecho de la parte norteamericana para someter la disputa al arbitraje. De acuerdo a lo anterior, la sentencia concluye que "en cualquiera de los casos mencionados en dicha cláusula este Tribunal serí incompetente".

En otra ocasión, el contrato que contenía la cláusula arbitral, se había celebrado entre una empresa chilena y una sociedad italiana. ${ }^{19}$ La empresa chilena dedujo una demanda de cobro de pesos ante un tribunal ordinario de Antofagasta, frente a lo cual la parte contraria planteó un incidente de nulidad de todo lo obrado por incompetencia del tribunal, el que fue acogido. La disputa acerca de la aplicabilidad de la cláusula arbitral llegó a la Corte Suprema por la vía de la casación en el fondo. El máximo tribunal confirmó la decisión de la primera instancia que remitía a las partes de un acuerdo arbitral al arbitraje.

La parte recurrente de casación buscaba revivir una antigua discusión acerca del supuesto carácter ilícito de la sumisión a jurisdicciones extranjeras. El precepto que había dado lugar a dudas interpretativas de ese tipo es el artículo 1462 del Código Civil, el que declara que hay objeto ilícito "en todo lo que contraviene al derecho puiblico chileno. Asi, la promesa de someterse en Chile a una jurisdicción no reconocida por las leyes chilenas, es nula por el vicio del objeto".

Sin embargo, a inicios del mismo año 2008, la Corte Suprema ya había confirmado que las cláusulas de sumisión a los tribunales ordinarios extranjeros eran perfectamente lícitas. ${ }^{20}$

19. Corte Suprema, Rol N 2026-2007, 28 de julio de 2008.

20. Corte Suprema, Rol N ${ }^{*} 5553-2002,22$ de cnero de 2008. 
En aquella ocasión, la conclusión de la Corte fue la siguiente:

"Que si bien se ha discutido la validez de la sumisión a una jurisdicción extranjera pactada entre particulares, lo cierto es que en el ejemplo que se da en el precepto recién citado, lo que se prohibe es someterse a una jurisdicción no reconocida por las leyes chilenas, puesto que las jurisdicciones extranjeras sí se encuentran reconocidas por las leyes chilenas como aparece de los artículos 242 y siguientes del Código de Procedimiento Civil".

Siguiendo con esta tendencia en el fallo en análisis, la Corte Suprema recurrió a los principios generales del Derecho Internacional Privado para determinar que

"el ordenamiento nacional reconoce explícitamente la posibilidad que los particulares estipulen someter las controversias que de la aplicación de un contrato internacional pudieran derivarse, al conocimiento de tribunales extranjeros, sean ellos ordinarios o arbitrales. Por ende, ningún objeto ilícito hay en la cláusula del contrato suscrito entre las partes, en virtud de la cual acuerdan entregar el conocimiento de los eventuales litigios que de éste se pudieran suscitar, a un tribunal italiano y, por lo mismo, no comete error de derecho la sentencia que declara la incompetencia del tribunal ante el cual se interpuso la demanda para conocer del litigio promovido".

Las sentencias dictadas muestran un reconocimiento del valor vinculante de los acuerdos de arbitraje por parte de los tribunales chilenos y sólo cabe esperar que los fallos futuros en esta materia se apoyen no tan solo en los principios jurídicos generales, sino que más bien recurran a las disposiciones explícitas de la Ley $\mathrm{N}^{\mathrm{0}} 19.971$. 


\section{Medidas Cautelares}

Acorde a lo estipulado en el art. 9 de la Ley $N^{\circ} 19.971$, "no será incompatible con un acuerdo de arbitraje que una parte, ya sea con anterioridad a las actuaciones arbitrales o durante su transcurso, solicite de un tribunal la adopción de medidas cautelares provisionales ni que el tribunal conceda esas medidas". Por lo tanto, los tribunales ordinarios de Chile tienen competencia para dictar medidas cautelares en apoyo a arbitrajes. Lo anterior también rige cuando el tribunal arbitral ya se había constituido o cuando la sede del arbitraje se encuentre en un país extranjero. Se conocen por lo menos dos fallos a través de los cuales, los tribunales domésticos cumplieron con esa labor de asistencia al arbitraje comercial internacional. En el primero de los casos, la petición de medidas cautelares se presentó previo a solicitar un arbitraje ante la Cámara de Comercio Internacional.21 En el segundo caso, dichas medidas fueron otorgadas en relación a un arbitraje constituido en el extranjero. ${ }^{22}$

Asimismo, en una sentencia reciente, la Corte Suprema precisó que una orden procesal interlocutoria dictada por un tribunal arbitral extranjero no puede ser reconocida en Chile a través del procedimiento de exequátur..$^{23} \mathrm{La}$ solicitud de exequátur recayó en una resolución dictada en un procedimiento arbitral en EE.UU. En el acuerdo de arbitraje, las partes convinieron que cualquier disputa entre ellas sería sometida a un arbitraje de tres árbitros, que se llevaría a efecto bajo las normas de la Asociación Americana de Arbitraje. Las partes establecieron también que cualquier resolución dictada por el panel arbitral estaría sujeta a los términos de la Convención de Nueva York y que cualquier fallo arbitral entregado por el panel de árbitros sería definitivo y vinculante para las empresas.

21. $28^{\circ}$ Juzgado Civil de Santiago, Rol N C-5243-2005, de 26 de mayo de 2005.

22. $26^{\circ}$ Juzgado Civil de Santiago, Rol N ${ }^{\circ}$ C-24011-2009, 24 de agosto de 2009.

23. Corte Suprema de Chile, Rol N 5468-2009, 11 de mayo de 2010. 
Una de las partes había solicitado al tribunal arbitral una medida precautoria tendiente a garantizar el efectivo cumplimiento de la obligación de no competir que recaía sobre la contraria. El panel arbitral decretó la medida precautoria solicitada, ordenándole a la parte demandada abstenerse de ejecutar diversas conductas en relación con los trabajadores o clientes de la parte demandante y con la información confidencial y secretos comerciales de esta última.

La Corte Suprema hizo hincapié en que la normativa relevante vigente en Chile se aplicaba al reconocimiento de sentencias dictadas por tribunales extranjeros, así como a los laudos arbitrales, en cambio dichas normas no son aplicables al cumplimiento de medidas cautelares dictadas por tribunales extranjeros. A juicio de la Corte,

"no cabe duda alguna que la resolución de cuyo cumplimiento se trata, no constituye, decisión o fallo que resuelva la cuestión principal de la que conoce el tribunal arbitral que lo dictó. Sin embargo, como también podría sostenerse que se trata de una sentencia interlocutoria de aquéllas que fallan un incidente del juicio, sea estableciendo derechos permanentes a favor de las partes, sea que resuelva sobre algún trámite que deba servir de base en el pronunciamiento de una sentencia definitiva o interlocutoria, resulta pertinente, examinar el contexto jurisdiccional en que fue emitido".

Al estudiar los antecedentes del caso, la Corte determinó que se trataba de una orden precautoria preliminar en contra de la demandada y que al acogerla, el tribunal arbitral había manifestado "que esta Orden Precautoria Preliminar se prorrogará y no vencerá hasta que este Tribunal dicte una nueva resolución o hasta que las partes convengan algo distinto". A juicio de la Corte Suprema, de lo analizado resulta evidente que la materia del exequátur no es una sentencia interlocutoria que establezca derechos permanentes, desde que el propio tribunal que la dictó, le dio el carácter de preliminar y porque, en definitiva, las medidas precautorias son esencialmente provisionales. Puede argüirse que al aco- 
ger la petición del exequátur, la concreción y mantenimiento en el tiempo de dichas medidas llevaría a decidir desde ya, acerca de las principales peticiones planteadas en la demanda. Por estos motivos, la petición de exequátur fue denegada.

Esta decisión del máximo tribunal nos permite concluir que el procedimiento de exequátur no es aplicable a las medidas cautelares dictadas por los tribunales arbitrales extranjeros. La solicitud de tales medidas debe presentarse directamente ante los tribunales chilenos, según lo que se desprende del artículo 9 de la Ley $\mathrm{N}^{\mathrm{o}} 19.971$.

\section{RECONOCIMIENTO DE SENTENCIAS ARBITRALES EXTRANJERAS}

En los últimos años, la Corte Suprema de Chile ha tenido que resolver sobre una serie de solicitudes de reconocimiento de sentencias arbitrales extranjeras. Hasta el momento, el máximo tribunal ha acogido todas las peticiones del exequátur presentadas.

Uno de los fallos más ilustrativos y completos recayó sobre la solicitud del exequátur de una sentencia arbitral pronunciada en Brasil. ${ }^{24} \mathrm{El}$ fallo de la Corte Suprema rechazó una serie de argumentos de la parte demandada, con los cuales pretendía se negara el reconocimiento del laudo arbitral. En primer lugar, el demandado alegaba la falta de validez de la cláusula compromisoria por su ambigüedad y por ser incompleta e imprecisa. Sin embargo, estos planteamientos fueron previamente desestimados por un tribunal ordinario de São Paulo, el que confirmó la validez de la cláusula compromisoria y fijó el procedimiento que permitía suplir sus deficiencias. Aquella sentencia del tribunal ordinario confirmando la validez del acuerdo arbitral, había sido objeto de recursos posteriores. Ello a juicio del demandado

24. Corte Suprema, Rol N ${ }^{\circ} 6615-2007$, 15 de septiembre de 2008.

278 Revista Ecuatoriana de ARbitraje 
significaba que el laudo arbitral no se encontraba ejecutoriado. Frente a ese planteamiento, la Corte chilena subrayó que la sentencia objeto del procedimiento de exequátur era el laudo arbitral y no la sentencia del tribunal ordinario brasileño que se había pronunciado sobre la validez de la cláusula. Según la ley brasileña, el plazo para pedir la nulidad del laudo era de 90 días y no existían antecedentes de que se hubiera entablado un procedimiento de esta índole.

El segundo grupo de argumentos del demandado apuntaba a que la realización del procedimiento arbitral en el idioma portugués le impedía hacer valer sus derechos y constituía una violación del debido proceso. El planteamiento fue desestimado por la Corte, ya que el demandado había sido "personalmente notificado de la acción, contestó la demanda, dedujo la reconvención y opuso excepciones, fue patrocinado por un estudio jurídico y notificado de la sentencia, respecto de la cual no se alzó".

Por último, el demandado invocaba la excepción del orden público, argumentando que la sentencia arbitral aplicaba intereses sobre intereses, lo cual estaría prohibido por la legislación nacional, violando, asimismo, otras normas del derecho chileno con respecto al pago de intereses. Frente a ello, el informe de la Fiscal Judicial indica que, en la legislación actual de Chile, la institución de los intereses compuestos está expresamente reconocida por el artículo 9 de la Ley $N^{\circ} 18.010$ que Establece Normas para las Operaciones de Crédito y otras Obligaciones de Dinero. Sin perjuicio de ello, la sentencia del máximo tribunal señala que las alegaciones del demandado sobre el cálculo de interés "constituyen una alegación de fondo, que escapa del control del exequátur, por lo que no corresponde a este Tribunal pronunciarse sobre la materia sino a aquél que conozca de la ejecución del fallo".

De manera semejante se desarrolló la argumentación en un procedimiento de exequátur con respecto de una sentencia arbitral dictada con sede en EE.UU. ${ }^{25}$ En su análisis, la Corte Suprema partió de la premisa que la función del exequátur con- 
sistía en "verificar el cumplimiento de ciertos requisitos mínimos y no se encuentra destinado, de manera alguna, a analizar la justicia o injusticia intrínseca de la sentencia de modo que de manera alguna constituye una instancia de revision de lo alli resuelto".

El fallo, junto con invocar la Ley $\mathrm{N}^{\circ} 19.971$, recurrió a la Convención de Nueva York. La Corte descartó analizar la excepción fundada en que no se había acreditado la existencia y reconocimiento en los Estados Unidos o en Chile de la sociedad demandante, ni tampoco se ha confirmado a quién corresponde la representación de ésta. Señaló que dicha causal no se encontraba dentro de aquellas consagradas en los artículos IV y V de la Convención de Nueva York y que ese asunto debió haber sido discutido en el procedimiento arbitral.

El máximo tribunal estimó que la parte demandada no se había visto impedida de hacer valer sus derechos, dado que participó en el arbitraje, opuso la excepción de contrato no cumplido, presentó una demanda reconvencional, la que fue acogida en parte, y rindió pruebas documental y testimonial. Asimismo, subrayó que en el contexto del procedimiento de exequátur no era pertinente efectuar una revisión de la solución del fondo del asunto adoptada por los árbitros extranjeros o evaluar la ponderación que ellos hicieron de las pruebas. Agrega la sentencia que

"a idéntica conclusión se arriba si se examina la alegación de supuesta falta de imparcialidad del tribunal arbitral, reclamada por [la parte] oponente, desde que su fundamento se lo hace consistir en simples conjeturas, las cuales, a su vez, se construyen sobre la base de una decisión que considera injusta".

Frente al argumento de la demandada de que el laudo arbitral carecería de carácter obligatorio o definitivo, la Corte Suprema observó que dicha sentencia arbitral había sido confirmada por el Tribunal del Distrito Sur de Nueva York, motivo por

25. Corte Suprema de Chile, Rol N $3225-2008,8$ de septiembre de 2009. 
el cual "puede concluirse con certeza que se encuentra justificado que aquél es obligatorio para quienes han sido partes en dicho compromiso".

Por último, la decisión más reciente recayó en una sentencia dictada en un proceso arbitral administrado por la Corte de Arbitraje Internacional de Londres. En ese caso, la parte demandada en el arbitraje, si bien había participado en la designación del árbitro de común acuerdo, con posterioridad no intervino en el proceso arbitral, dictándose la sentencia arbitral en su contra. El procedimiento de exequátur, asimismo, fue tramitado en rebeldía de la parte vencida en el arbitraje.

En su fallo, la Corte dedica una especial atención a la determinación de la normativa aplicable al reconocimiento de las sentencias arbitrales extranjeras. Como es habitual en su jurisprudencia, pasa revista del sistema chileno sobre cumplimiento de los fallos extranjeros, cuyos pilares están sentados en los artículos 242 a 251 del Código de Procedimiento Civil. Dentro de ese sistema denominado por la Corte "en cascada", se aplica la reciprocidad creada por los tratados existentes, la reciprocidad legal o interpretativa y, en ausencia de esos antecedentes, pasa a regir el criterio de regularidad internacional. La Corte sostuvo que

"ante los claros términos de la Ley N ${ }^{\circ} 19.971$, la regularidad de la sentencia cuya autorización para el cumplimiento en Chile se requiere, debe ser estudiada al tenor de la normativa, considerando especialmente los artículos 35 y 36, todo sin dejar de tener presente la Convención de Nueva York, puesto que fue este marco regulatorio el atendido y sobre la base de cuya aplicación se desarrolló el arbitraje".

La parte requirente del exequátur sostenía que la sentencia arbitral reunía todas las condiciones legales para que éste sea otorgado, y que la parte demandada no había formulado objeción alguna. El máximo tribunal corroboró la existencia de una cláusula arbitral incluida en los contratos objeto de la controversia y que la demandada 
"no se vio impedida de ejercer su derecho a la defensa sino que simplemente decidió, de forma voluntaria, mantenerse rebelde en aquél procedimiento, no obstante haber sido debidamente emplazada, actitud ésta que no puede, de manera alguna, identificarse con indefensión".

Por las razones expuestas, la solicitud de exequátur fue acogida y el cumplimiento de la sentencia arbitral autorizado.

\section{7. ¿CARÁCTER EJECUTORIAdo de LA SENTENCIA ARBITRAL EXTRANJERA? RECONOCIMIENTO DE UNA SENTENCIA SUJETA AL PROCESO DE ANULACIÓN EN EL PAÍS DE ORIGEN}

En las sentencias citadas en el acápite anterior, se percibe un grado de inquietud de la Corte Suprema por confirmar el carácter ejecutoriado del fallo arbitral. Dicha práctica de la Corte Suprema, la de solicitar un certificado de ejecutoria de las sentencias extranjeras, tiene su origen en lo previsto por el artículo 245 del CPC chileno, la norma que contempla los criterios que deben satisfacer los fallos dictados fuera del territorio nacional. El numeral 4 de este precepto requiere que la sentencia extranjera se encuentre ejecutoriada en conformidad a las leyes del país en que haya sido pronunciada. A mayor abundamiento, el artículo 246 del CPC proclama que en el caso de las resoluciones expedidas por árbitros extranjeros, "se hará constar su autenticidad y eficacia por el visto bueno u otro signo de aprobación emanado de un tribunal superior ordinario del país donde se haya dictado el fallo".

En materia de arbitraje, dicho requisito debe haber quedado descartado a partir de la ratificación de la Convención de Nueva York, con mayor razón cuando el artículo 242 del mismo Código hace primar los tratados internacionales por sobre las estipulaciones domésticas. En la jurisprudencia reciente, dicho requisito no fue un obstáculo para el reconocimiento de los laudos arbitra- 
les, sin embargo, seguía siendo invocado por la Corte. ${ }^{26}$ Dicha práctica se ilustra, por ejemplo, en el contexto de un exequátur otorgado en el año 2007 a una sentencia arbitral dictada en Argentina. ${ }^{27} \mathrm{La}$ Corte, aunque no exigió la observancia estricta del artículo 246 del CPC, tomó expresamente en consideración las certificaciones emanadas de los tribunales argentinos y de la institución administradora del arbitraje, en las que se daba cuenta del rechazo de los recursos interpuestos contra la sentencia arbitral. Finalmente, la Corte concluyó que, constando que la sentencia arbitral se encontraba ejecutoriada y cumpliéndose los requisitos del artículo IV de la Convención de Nueva York, se concedía el exequátur.

Frente a esta práctica resulta decisiva la innovadora postura que la Corte Suprema adoptó en un procedimiento de exequátur de una sentencia arbitral dictada en Francia, que se encontraba sujeta a un proceso de anulación en el país de su origen. ${ }^{28} \mathrm{La}$ parte demandada en el arbitraje se opuso al reconocimiento de la sentencia arbitral invocando, entre otros motivos, que el laudo arbitral no era obligatorio aún para las partes o que había sido anulado o suspendido por un tribunal del país de su dictación (art. V.I.e. de la Convención de Nueva York y art. 36.1.a.v de la LACI), debido a que la sentencia arbitral se encontraba sujeta a un procedimiento de anulación pendiente ante la Corte de Apelaciones de París.

Según el derecho francés, la interposición del recurso de nulidad tiene para el laudo arbitral efectos suspensivos. Sin embargo, la Corte Suprema sostuvo que la ley aplicable al reconocimiento de esa sentencia extranjera era la ley chilena, y por ende las consecuencias específicas previstas por el derecho francés para esos efectos, no tenían relevancia. La existencia de un proceso de anulación pendiente no era suficiente para denegar el

26. Ver, por ejemplo, Corte Suprema, Rol N ${ }^{\circ} 6615-2007,15$ de septiembre de 2008, Corte Suprema, Rol $N^{\circ} 3225-2008,8$ de septiembre de 2009.

27. Corte Suprema, Rol N ${ }^{\circ} 6600-2005,11$ de enero de 2007

28. Corte Suprema, Rol N 5228-2008, 15 de diciembre de 2009. 
exequátur, sino que era necesario que se acreditara la correspondiente anulación o suspensión del fallo.

Por último, la Corte se refirió a que el laudo era obligatorio para las partes acorde a lo establecido en el Reglamento aplicable al procedimiento arbitral. En particular, el máximo tribunal proclamó:

"De otra parte, el Reglamento de Arbitraje de la Cámara de Comercio Internacional señala en su artículo $28 \mathrm{~N}^{\circ} 6$ que: 'Todo Laudo es obligatorio para las partes. Al someter su controversia a arbitraje según el Reglamento, las partes se obligan a cumplir sin demora cualquier Laudo que se dicte y se considerará que han renunciado a cualesquiera vías de recurso a las que puedan renunciar válidamente'. De dicha disposición se sigue que la sentencia dictada por dicho tribunal resulta irreformable en el sistema previsto por esa normativa, de forma tal que el recurso formulado ante la justicia de Francia, no suspende los efectos de aquella, la que mantiene su vigencia y es posible ejecutarla en tanto no exista resolución de contrario, desde el momento que la tramitación dispuesta en el marco de esa Cámara arbitral lo fue en un contrato internacional suscrito por una entidad bancaria alemana y un mutuario chileno, quienes han recurrido al organismo arbitral y no al sistema judicial francés, por todo lo cual esta alegación también debe ser rechazada".

La solución más adecuada en este contexto sería seguir con esta misma línea argumentativa, reforzando el carácter obligatorio de las sentencias arbitrales extranjeras.

\section{Conclusión}

La jurisprudencia analizada ilustra una postura consistente de apoyo por parte de los tribunales ordinarios chilenos hacia el arbitraje comercial internacional. La Ley $\mathrm{N}^{\circ} 19.971$ ha tenido una acogida favorable en la jurisprudencia chilena. Es de esperar que 
en la medida en que el número de los casos internacionales crez$\mathrm{ca}$, el vocabulario conceptual y teórico de las Cortes se desarrolle y profundice, siempre con miras de trabajar hacia la consagración de Chile como una atractiva sede de arbitrajes internacionales. 
